\title{
ОСАДКОНАКОПЛЕНИЕ В ПЯРНУСКОМ ЗАЛИВЕ
}

Пярнуский залив занимает важное место в экономической жизни Эстонской ССР, являясь одновременно районом морского промысла и отдыха. Кроме того, Пярнуский порт один из крупнейших в республике, и, следовательно, его акватория имеет немаловажное значение для судоходства. Это обусловливает необходимость всестороннего изучения не только природы, но и осадконакопления в пределах Пярнуского залива.

В ряде работ по изучению Балтийского моря в целом (Геология..., 1976), а также отдельных его частей (Горшкова, 1961) дается весьма общее представление о характере донных осадков рассматриваемой акватории. В некоторых гидробиологических публикациях (Ярвекюльг, 1979 и др.) отмечается, что «в заливе преобладают песчаные, галечные, глинистые и каменистые грунты; почти полностью отсутствуют отложения ила. На обширных площадях отложения глины покрыты слоем песка и гравия толщиной в несколько сантиметров». Нами (Лутт, 1985) охарактеризованы некоторые структурные особенности и выявлены основные черты минерального состава песчано-алевритового компонента донных осадков залива.

Для лучшего понимания современного осадконакопления в Пярнуском заливе следует коротко остановиться на его гидрологии. Наиболее влиятельными с точки зрения седиментации являются режимы волнения и течений, а также условия замерзания. Максимальная высота волн в устьевой области залива при ветрах южных направлений со скоростью $24 \mathrm{~m} / \mathrm{c}$ в течение 0,5 ч или $10-15 \mathrm{~m} / \mathrm{c}$ в течение 10 ч может доходить до 2,5 м (Буданова, 1967). Из-за мелководности бассейна (в устье залива до 12 м, в центральной части до 7 м) волнение нередко достигает дна, вызывая его размыв, а также перемещение седиментационного материала. Режим течений залива изучен явно недостаточно - известно лишь, что течения возникают и развиваются в результате воздействия стока рек, ветра и общей циркуляции вод в Рижском заливе; схема преобладающих течений выглядит следующим образом: воды Рижского залива входят в Пярнуский залив вдоль западного берега и выходят широкой полосой по восточной половине залива, чаще всего захватывая всю толщу воды. Скорость течений доходит до $21 \mathrm{~cm} / \mathrm{c}$ при устойчивых ветрах $6-8$ м/с. Пярнуский залив замерзает ежегодно на 3,5-4 месяца, максимальная толщина льда достигает $70 \mathrm{~cm}$, а в случае возникновения подсовов - до 114 см (Буданова, 1967). Лед при торошении может влиять на морское дно до глубины нескольких метров, выталкивая оттуда рыхлый материал или даже крупные валуны. Разрыхлению и размыву как донного, так и берегового материала способствует и пере. мещение льда.

Коренные породы, представленные на побережье Пярнуского залива силурийскими доломитами и девонскими песчаниками, на дневную поверхность нигде не выходят. Они покрыты в основном мореной последнего оледенения, над которой залегает ленточная глина. Местами плейстоценовые отложения покрыты песчано-алевритовыми осадками Литоринового и Лимниевого морей (Раукас, 1978), 
Дно Пярнуского залива покрыто голоценовыми морскими осадками небольшой мощности. Согласно применяемой нами классификации морских донных осадков (Безруков, Лисицын, 1960; Лутт, 1985), в пределах рассматриваемой акватории целесообразно различать грубообломочные (гравий и галечник) осадки, песок и алеврит (рис. 1). Более крупные обломки (валуны, глыбы), по нашим материалам, встречаются лишь спорадически среди более мелких осадков.

Гравий и галечник прослеживаются полосами шириной в несколько километров вдоль восточного и западного берегов до глубнны 4-5 м, преимущественно в южной половине залива. Небольшими пятнами они обнаружены также среди более тонких осадков несколько глубже. Пески занимают около половины площади и подразделяются на крупную, среднюю и мелкую разновидности (первые две на рис. 1 показаны вместе). Крупно- и среднезернистый песок наблюдается глубже грубообломочных осадков, при этом одна узкая полоса тянется вдоль восточного берега, а другая - более широкая - вдоль западного, отдельные небольшие пятна наблюдаются и в осевой части залива. Мелкий песок прослеживается на дне рассматриваемой акватории несколькими языками сложной конфигурации до глубины 10 м (рис. 1). Алевритовые (преимущественно крупный алеврит) осадки преобладают в осевой части залива, образуя два основных ареала. Первый из них наблюдается в южной части акватории и протягивается несколькими языками к северу, а второй расположен в северной части залива, где зона развития алеврита начинается от устьевой области рек Аудру и Пярну и протягивается несколькими языками на юг и запад.

В пределах Пярнуского залива отчетливо прослеживается дифференциация седиментационного материала по крупности (рис. 2-7). Содержание грубообломочного компонента в осадках большей части акватории менее $10 \%$ (рис. 2), а нередко и меньше $5 \%$. Завышенное содержание отмечается лишь на нескольких небольших участках в

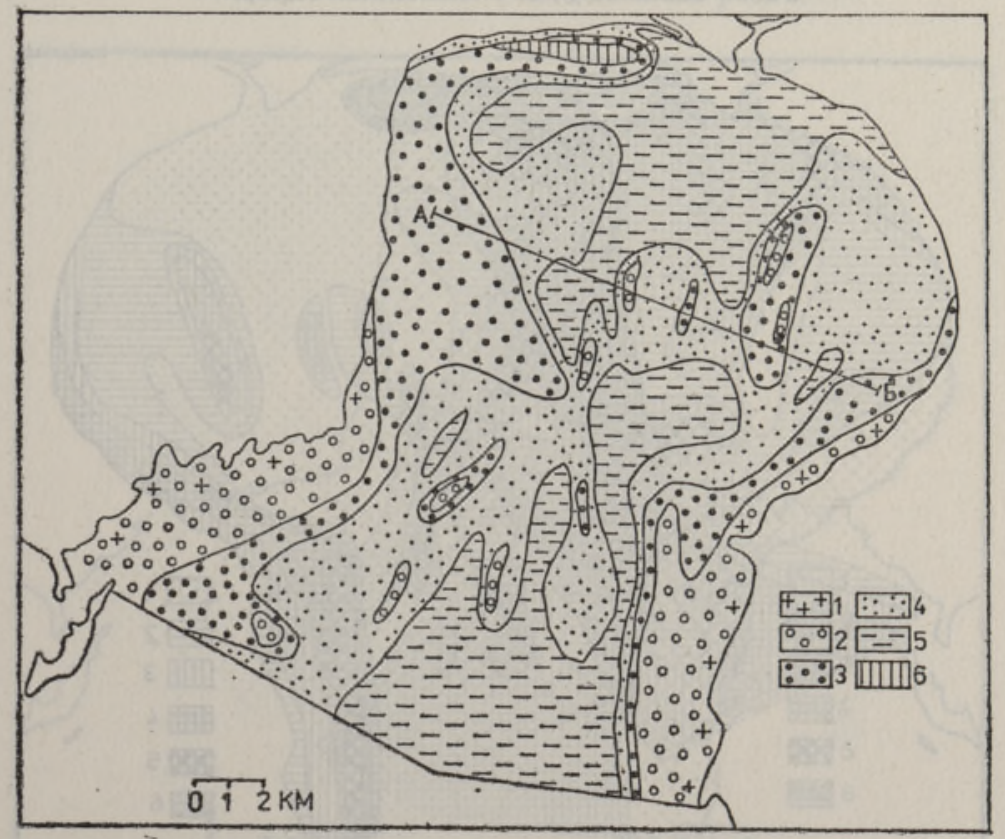

Рнс. 1. Распространение донных осадков Пярнуского залива: 1 - валуны, $2-$ гравий и галечник, 3 - крупный-средний песок, 4 - мелкнй песок, 5 - алеврит, 6 - ленточная глина (АБ - положение разреза), 
центральной части залива. Количество фракции крупнее 1 мм закономерно увеличивается в прибрежной полосе, достигая максимума (до $95,3 \%)$ в его юго-западной части. Более широко распространена крупнои среднепесчаная фракция $(1,0-0,25$ мм), но очень высокие (более $75 \%$ )

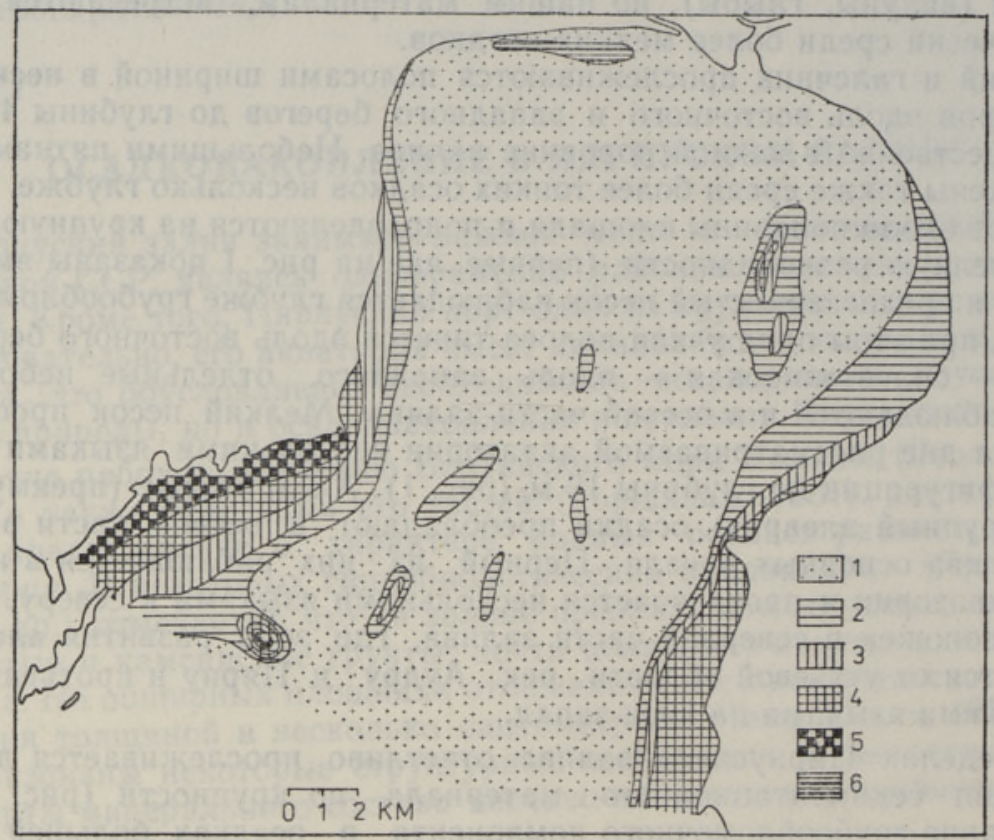

Рис. 2. Распределение фракции крупнее 1,0 мм в поверхностном (0-10 см) слое донных осадков Пярнуского залива: $1-$ менее $10 \%, 2-10-25 \%, 3-25-50 \%, 4-50-75 \%$, 5 - более $75 \%, 6$ - ленточная глина.

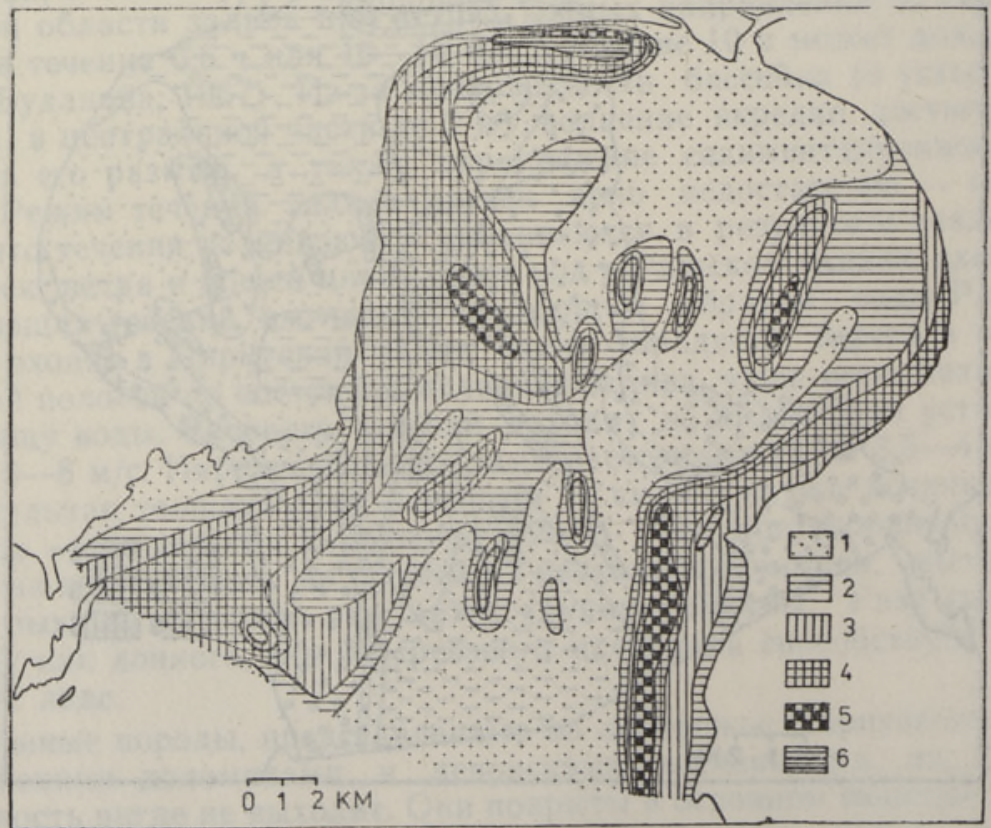

Рис. 3. Распределение фракции $1,0-0,25$ мм в поверхностном слое донных осадков Пярнуского залива. Усл. обозн, см. рис. 2. 
ее концентрации прослеживаются также сравнительно небольшими полосами и пятнами (рис. 3). Высокие (50-75\%) содержания характерны главным образом западной части залива в виде довольно широкой полосы; в восточной части полоса аналогичных содержаний значительно уже. Наиболее распространенной из песчаных фракций в осадках Пярну-

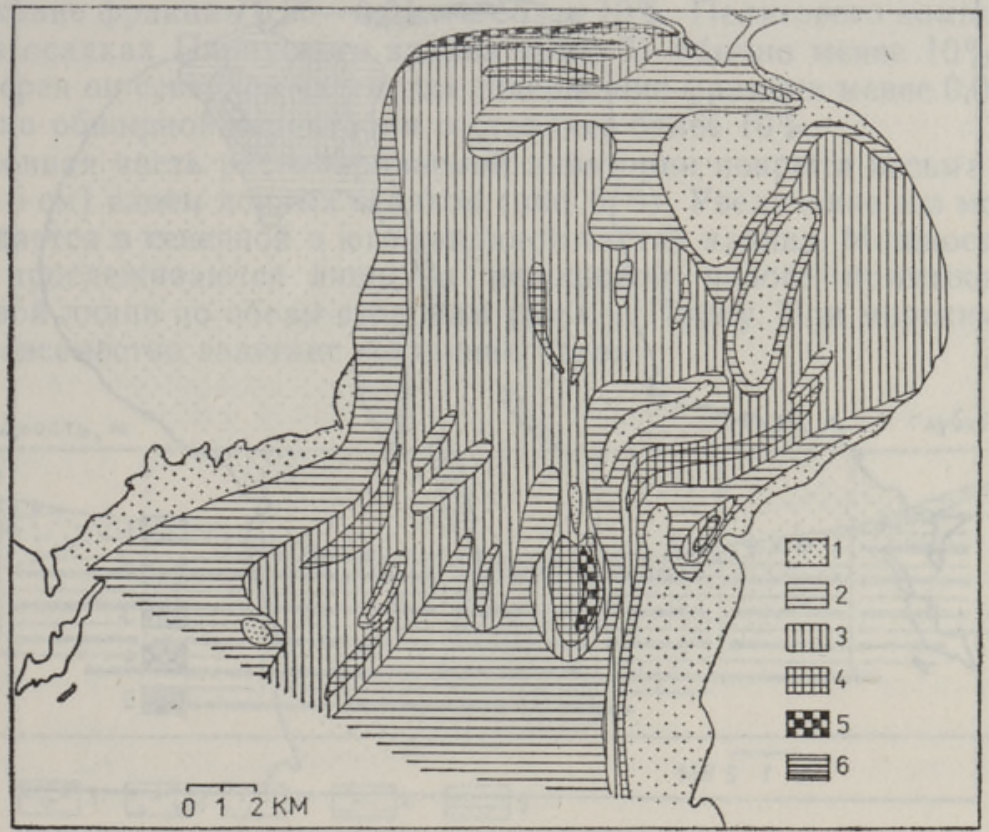

Рис. 4. Распределение фракции $0,25-0,1$ мм в поверхностном слое донных осадков Пярнуского залива. Усл. обозн. см. рис. 2.

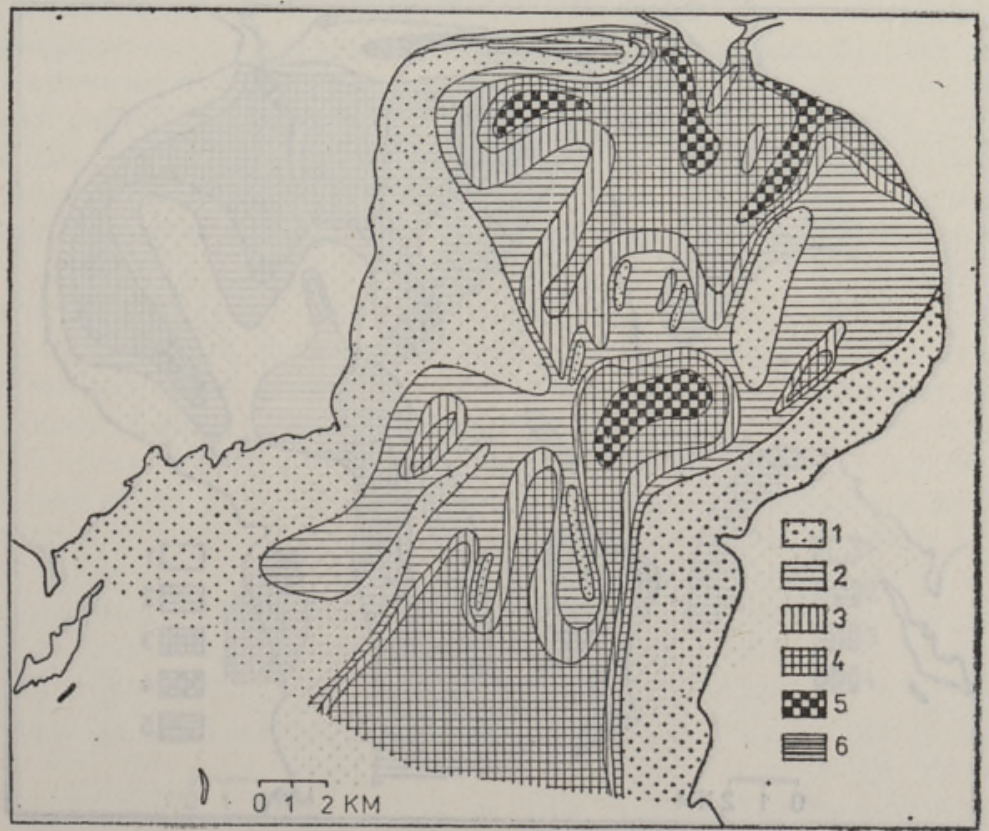

Рис. 5. Распределение фракции $0,1-0,05$ мм в поверхностном слое донных осадков Пярнуского залива. Усл. обозн. см. рис. 2. 
ского залива является мелкопесчаная (рис. 4), содержание которой редко ниже $10 \%$. В большинстве случаев ее количество от 25 до $75 \%$. Крупноалевритовый компонент (рис. 5) тяготеет преимущественно к осевой части залива. При этом площади с очень высоким (более $75 \%$ )

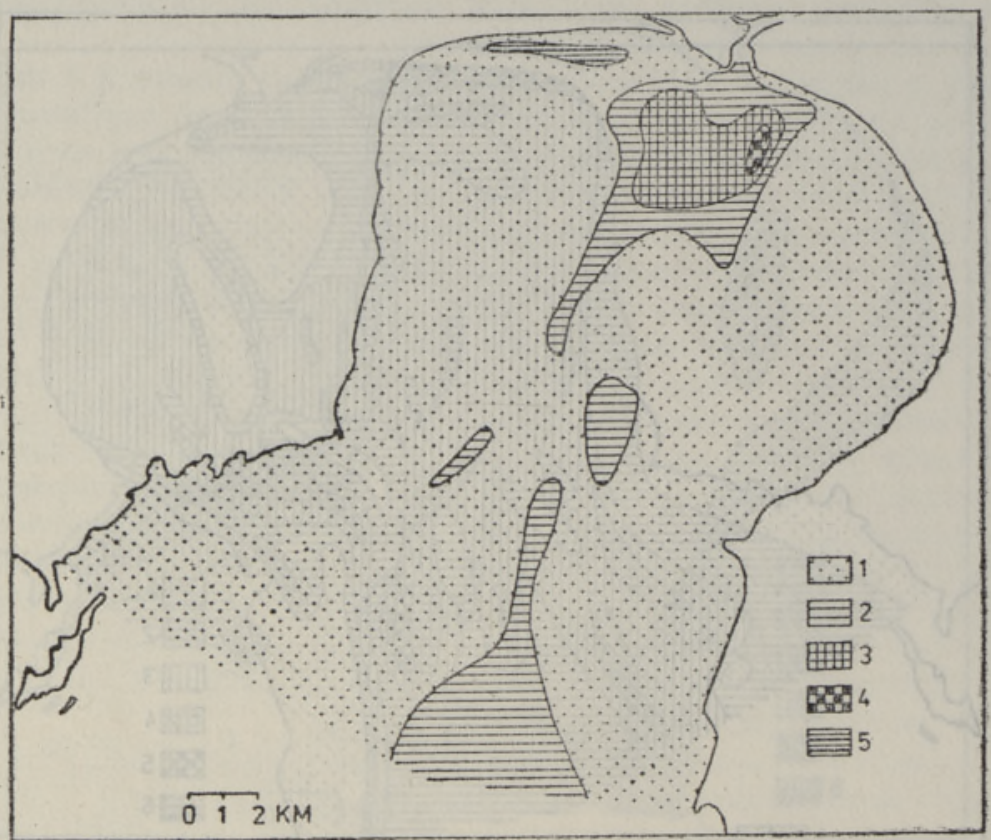

Рис. 6. Распределение фракцин $0,05-0,01$ мм в поверхностном слое донных осадков Пярнуского залива: 1 - менее $5 \%, 2-5-10 \%, 3-10-25 \%, 4-$ более $25 \%, 5$ ленточная глина.

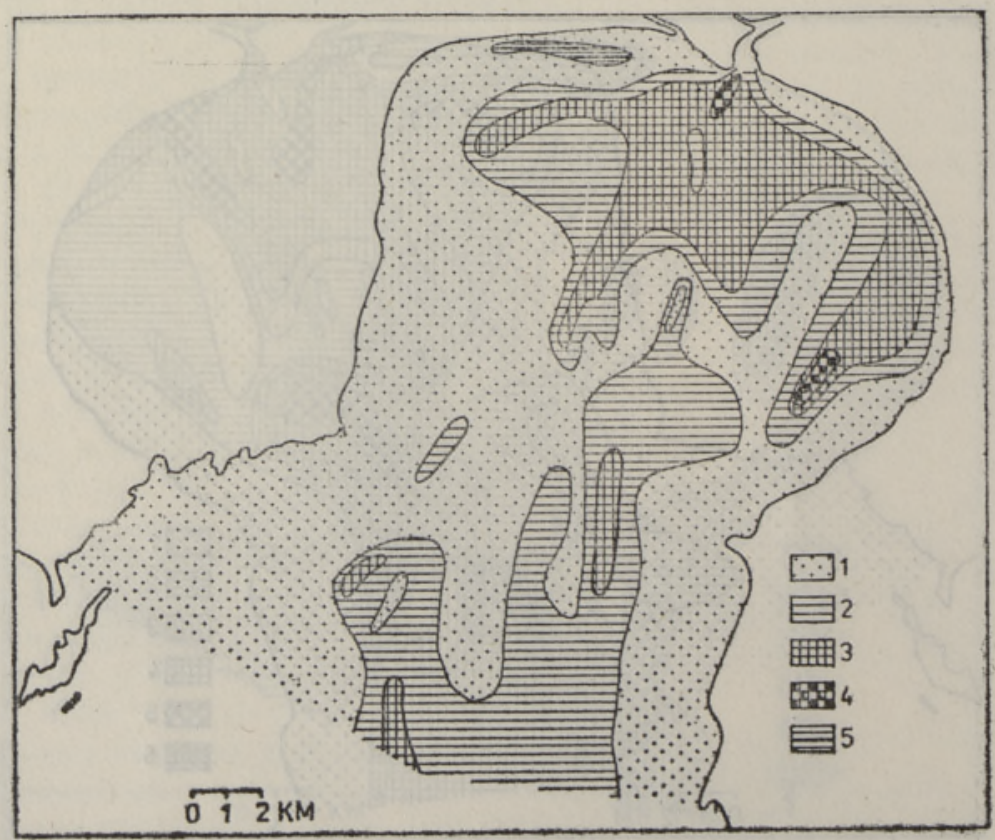

Рнс. 7. Распределение фракции менее 0,01 мм в поверхностном слое донных осадков Пярнуского залива. Усл. обозн. см. рнс. 6. 
его содержанием приурочены к устьевой области рек. Наблюдается постепенное уменьшение значения крупноалевритовой фракции от осевой части в сторону восточного и западного берегов. Роль мелкоалевритового компонента в поверхностном слое рассматриваемых осадков очень скромная, и, как правило, не превышает $5 \%$ (рис. 6). Лишь перед устьями рек прослеживается небольшой участок осадков, в которых содержание фракции 0,05-0,01 мм более $10 \%$. Пелитового компонента в донных осадках Пярнуского залива (рис. 7) обычно менее $10 \%$. Более характерен он северной части, где содержание фракции менее 0,01 мм на довольно обширной территории составляет более $10 \%$.

Основная часть рассматриваемой акватории покрыта весьма тонким (менее 5 см) слоем донных осадков (рис. 8,9 ). Увеличение его мощности наблюдается в северной и юго-западной частях залива. Мощности более 100 см прослеживаются лишь на неширокой полосе, примыкающей к береговой линии по обеим сторонам устья р. Пярну. Под морскими осадками повсеместно залегает ленточная глина.

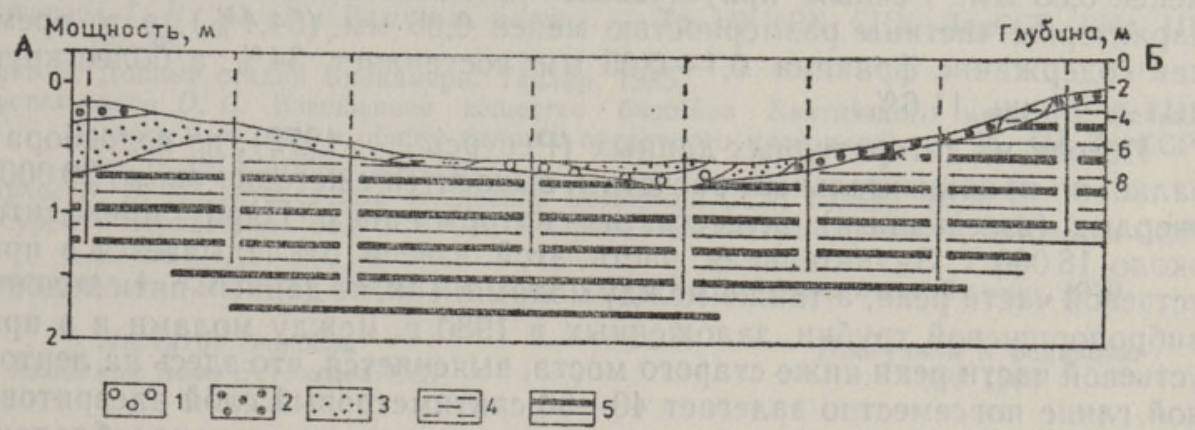

Рис. 8. Разрез по линии АБ: 1 - гравнй и галька, $2-$ крупный-средний песок, 3 мелкий песок, 4 - алеврит, 5 - ленточная глина.

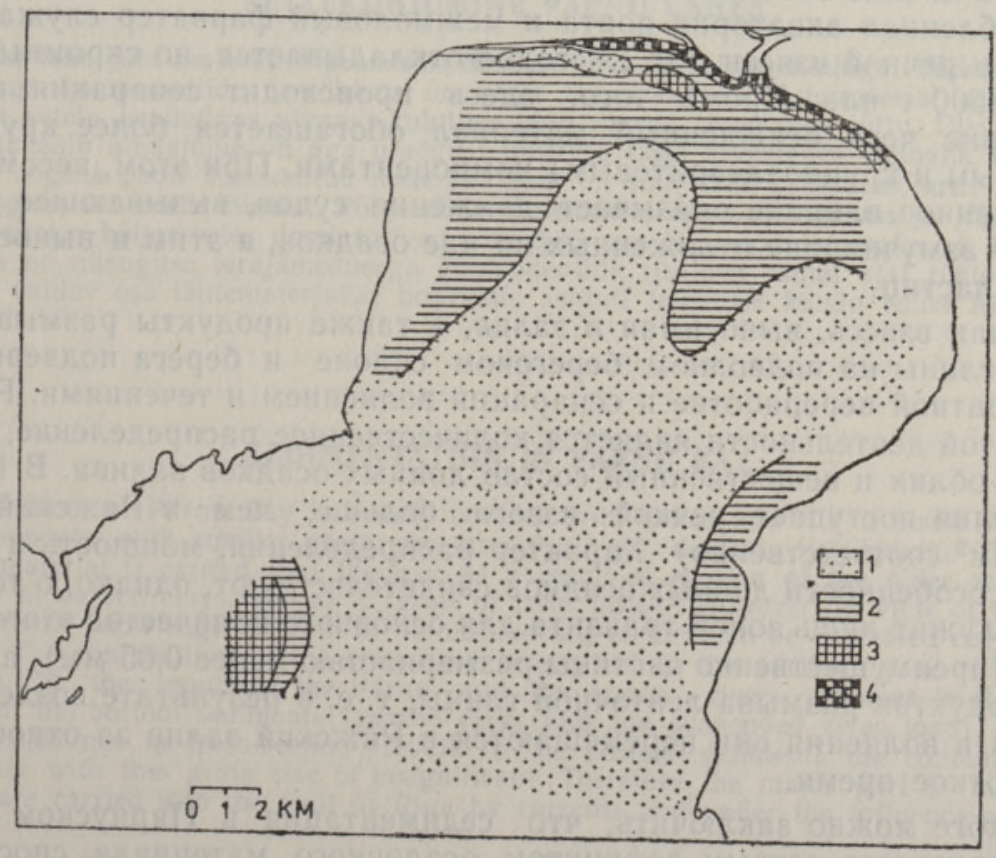

Рис. 9. Распределение мощностей донных осадков в Пярнуском заливе. $1-0-0,05$ м, $2-0,05-0,5$ м, $3-0,5-1$ м, $4-$ более 1 м. 
Приведенный материал позволяет выявить основные закономерности осадконакопления в Пярнуском заливе. Можно предполагать, что количество осадков, их состав и структурные особенности предопределяются главным образом количеством и характером исходного материала, поступающего в бассейн седиментации. Во время сильного волнения, достигающего дна залива, размыву подвергается в первую очередь маломощный слой песчано-алевритовых морских осадков, основная масса которых переходит во взвешенное состояние. При этом происходит дополнительная сепарация осадков, отложенных ранее, а также истирание поверхности подстилающей ленточной глины. Вследствие этого в залив поступает некоторое количество осадочного материала, в составе которого явно превалируют (около 90\%) частицы размерностью менее 0,05 мм. Реки (наиболее крупные из них Пярну и Аудру) также выносят в залив тонкозернистые компоненты. Әто подтверждается как данными по изучению взвеси, так и анализом аллювия в устье р. Пярну. При этом речная взвесь (Пустельников, 1976) полностью состоит из частиц размерностью менее 0,05 мм. Речным приустьевым и межмоловым осадкам также характерны частицы размерностью менее 0,05 мм $(54,4 \%)$, в то время как содержание фракции $0,1-0,05$ мм составляет $34 \%$, а более крупных - лишь $11,6 \%$.

Исходя из литературных данных (Ресурсы..., 1972), из водосбора в залив, по приблизительным расчетам, выносится ежегодно около 20000 т твердых (взвешенных) веществ, из которых на р. Пярну приходится около 18000 т. Значительная часть этой взвеси откладывается в приустьевой части реки, а также между молами. Так, по данным пяти колонок вибропоршневой трубки, заложенных в 1980 г. между молами и в приустьевой части реки ниже старого моста, выясняется, что здесь на ленточной глине повсеместно залегает 40-50-сантиметровый слой алевритовопелитовых осадков, в гранулометрическом спектре которых преобладают $(54,4 \%)$ характерные для речной взвеси частицы. Следует иметь в виду, что указанный слой образовался после дноуглубительных работ, проведенных в начале 1960-х гг., т. е. приблизительно за 20 лет, а искусственно углубленная акватория порта и межмоловый фарватер служат коллектором речной взвеси, где ежегодно откладывается, по скромным расчетам, 8600 т ила. Кроме того, здесь происходит сепарация взвеси, вследствие чего осажденный материал обогащается более крупными (песчаным и крупноалевритовым) компонентами. При этом, несомненно, определенное влияние оказывает движение судов, вызывающее многократное взмучивание отложенных на дне осадков, а этим и вынос более тонких частиц.

Речная взвесь, выносимая в залив, а также продукты размыва ленточной глины на подводном береговом склоне и берега подвергаются многократной переработке и сепарации волнением и течениями. Результатом этой деятельности является количественное распределение, структурный облик и вещественный состав донных осадков залива. В Пярнуский залив поступает речной взвеси больше, чем в Рижский (30 и 18,4 т/км² соответственно). Характер распределения, мощность и структурные особенности донных осадков свидетельствуют, однако, о том, что залив служит лишь зоной транзита для основного количества этого материала (преимущественно частицы размерностью менее 0,05 мм), а также для продуктов размыва ленточной глины, т. е. в результате воздействия течений и волнения они перемещаются в Рижский залив за относительно короткое время.

В итоге можно заключить, что седиментация в Пярнуском заливе характеризуется острым дефицитом осадочного материала, способного при существующих гидродинамических условиях образовать значительные скопления. Относительно крупные (более 0,05 мм) компоненты речных 
выносов накапливаются главным образом в вершине залива и в устьях рек, оседая на дне преимущественно восточного берега. Бо́льшая часть залива (рис. 9) покрыта песками и алевритом небольшой мощности. Это, видимо, остаточные продукты донных осадков более ранних стадий развития Балтики, а также ленточной глины. Определение количества седиментационного материала, продуцируемого размывом дна и берегов залива, на данном этапе исследований еще невозможно, хотя, по нашему мнению, его масса уступает речному выносу.

\section{ЛИ Т Е РА Т У Р А}

Безруков П. Л., Лисицын А. П. Классификация осадков современных морских водоемов. - Тр. Ин-та океанол. АН СССР, 1960, 32, 3-14.

Буданова B. А. Краткая гидрометеорологическая характеристика залива Пярну-лахт. Сб. работ Таллинской ГМО, 1967, вып. 5, 55-64.

Геология Балтийского моря. Вильнюс, 1967.

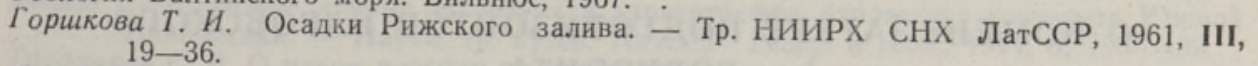

Лутт Я. Донные осадки Вяйнамери. Таллин, 1985.

Пустельников О. С. Взвешенное вещество бассейна Балтийского моря (2. Речная взвесь и ее роль в общем балансе осадочного материала). - Тр. АН ЛитССР, cep. Б, 1976, 5(96), 139-146.

Раукас А. В. Плейстоценовые отложения Эстонской ССР. Таллин, 1978.

Ресурсы поверхностных вод СССР. Т. 4. Прибалтнйский район, вып. 1, Эстонская ССР. Л., 1972.

Ярвекюльг А. А. Донная фауна восточной части Балтийского моря. Таллин, 1979.
Институт геологии
Академии наук Эстонской ССР
Поступнла в редакцию
$5 / \mathrm{V} 1986$

\section{J. LUTT}

\section{SETTEKUHJUMINE PARNU LAHES}

Pärnu lahe põhi on kaetud peamiselt õhukese liiva- ja aleuriidikihiga. Väiksema terajämedusega komponentide osatähtsus on väga tagasihoidlik. Settematerjal satub lahte vanemate setete, sealhulgas viirsavi kulutuse ning joggede sissekande tōttu. Ohe või teise teguri osakaalu hindamine on aga praegust uurituse taset arvestades võimalik vaid ligikaudselt. Jōgede poolt sissekantud materjali hulk on suur lahe põhjaosas, eriti Pärnu ja Audru jōgede suudmete lähedal. Pōhjasetete lähtematerjalis, s. o. viirsavis ja jôgede poolt sissekantavates hõljeainetes domineerivad alla $0,05 \mathrm{~mm}$ läbimõöduga osakesed. Põhjasetteis endis on niisuguse terajämedusega komponentide sisaldus samal ajal tühine. Seega kantakse valdav osa lähtematerjalist hoovuste, samuti lainetuse kaudu edasi Riia lahte.

\section{J. LUTT}

\section{SEDIMENTATION IN PÄRNU BAY}

The bottom of Pärnu Bay is mainly covered with sands and silt of small thickness. The components with smaller grain size are of a very modest distribution. The sedimentary material is carried into the bay as a result of erosion of the older sediments, especially of varved clays, and as a result of river inflow. However, in view of the level of our present knowledge the role of the influencing factors can be evaluated only approximately. The contribution of the river load is greatest in the northern part of the bay, especially in the mouth of the Pärnu and the Audru rivers, whereas in the initial deposits of the bottom sediments (varved clays and the suspended river load) particles components with in cross-section prevail. In the bottom sediments the content of the material are carried grain size is insignificant. Therefore the major part of the initial action. 